\title{
Catheter-directed interventions for pulmonary embolism
}

\author{
Mehrzad Zarghouni ${ }^{1}$, Hearns W. Charles ${ }^{2}$, Thomas S. Maldonado ${ }^{3}$, Amy R. Deipolyi ${ }^{4}$ \\ ${ }^{1}$ Department of Interventional Radiology, Memorial Hermann Memorial City, Houston, TX, USA; ${ }^{2}$ Department of Vascular and Interventional \\ Radiology, ${ }^{3}$ Department of Vascular Surgery, NYU Langone Medical Center, New York, NY, USA; ${ }^{4}$ Interventional Radiology Service, Memorial \\ Sloan Kettering Cancer Center, New York, NY, USA \\ Contributions: (I) Conception and design: M Zarghouni, AR Deipolyi; (II) Administrative support: HW Charles; (III) Provision of study material or \\ patients: HW Charles, TS Maldonado, AR Deipolyi; (IV) Collection and assembly of data: All authors; (V) Data analysis and interpretation: None; (VI) \\ Manuscript writing: All authors; (VII) Final approval of manuscript: All authors. \\ Correspondence to: Amy R. Deipolyi, MD, PhD. Interventional Radiology Service, Memorial Sloan Kettering Cancer Center, 1275 York Avenue, New \\ York, NY 10065, USA. Email: deipolya@mskcc.org.
}

\begin{abstract}
Pulmonary embolism (PE), a potentially life-threatening entity, can be treated medically, surgically, and percutaneously. In patients with right ventricular dysfunction (RVD), anticoagulation alone may be insufficient to restore cardiac function. Because of the morbidity and mortality associated with surgical embolectomy, clinical interest in catheter-directed interventions (CDI) has resurged. We describe specific catheter-directed techniques and the evidence supporting percutaneous treatments.
\end{abstract}

Keywords: Angiography; pulmonary embolism (PE); thrombolytic therapy

Submitted Jul 14, 2016. Accepted for publication Oct 20, 2016.

doi: $10.21037 / \mathrm{cdt} .2016 .11 .15$

View this article at: http://dx.doi.org/10.21037/cdt.2016.11.15

\section{Introduction}

Pulmonary embolism (PE) causes 100,000-180,000 deaths annually (1). Three-month mortality is $15 \%$ in all patients with PE, and nearly $50 \%$ in massive PE (2). The Food and Drug Administration (FDA)-approved treatments for $\mathrm{PE}$ include oral anticoagulants, systemic thrombolysis, aspiration thrombectomy using a Greenfield suction embolectomy catheter, and ultrasound-accelerated catheterdirected thrombolysis (3). Surgical thrombectomy can be performed for certain patients without significant comorbidities (4). Due to lack of universal surgical expertise and comorbidities commonly precluding surgery, surgical intervention is not ubiquitous. Because of the risk of hemorrhage with systemic thrombolysis, clinical interest in endovascular options has risen (4).

No dual-arm randomized control trials assess catheterdirected intervention (CDI) for treatment of PE. Data, though promising, consist of case series, single-arm trials, or studies with historical controls (Table 1). Despite the lack of evidence, many centers are developing multidisciplinary team approaches using systemic thrombolysis, surgical embolectomy, and CDI. In this review, we discuss catheterdirected techniques to treat symptomatic PE.

\section{Diagnosis and management of PE}

\section{Diagnosis}

For patients with suspected PE, computed tomography with $\mathrm{PE}$ protocol (CTPE) is the most widely accepted imaging tool (12). Though ventilation perfusion (VQ) scans can risk stratify patients with suspected PE, CTPE has superior sensitivity and specificity, provides information regarding PE chronicity, location, and laterality, and evaluates for right heart strain [defined as right ventricle $(\mathrm{RV}) / \mathrm{left}$ ventricle $(\mathrm{LV})$ ratio of $>0.9$, atrial septal bowing, and reflux of contrast via the inferior vena cava (IVC) and hepatic veins] and the rare presence of tumor thrombus $(13,14)$. CT can exclude other causes of chest pain and shortness of breath. Therefore, CTPE is the diagnostic modality of choice.

In acute $\mathrm{PE}$, cardiac markers including troponin and brain natriuretic peptide (BNP) predict morbidity and 
Table 1 Key studies regarding treatment of PE with systemic thrombolysis, catheter-directed therapy, and IVC filter placement

\begin{tabular}{|c|c|c|c|c|}
\hline Trial & Study type & Population & Arms & Findings \\
\hline $\begin{array}{l}\text { Meyer et al. (6), Pulmonary } \\
\text { Embolism THrOmbolysis (PEITHO) }\end{array}$ & $\begin{array}{l}\text { Randomized } \\
\text { controlled }\end{array}$ & $\begin{array}{l}1,005 \text { patients } \\
\text { with submassive } \\
\text { PE }\end{array}$ & $\begin{array}{l}\text { Arm 1: systemic thrombolysis } \\
\text { and anticoagulation; arm 2: } \\
\text { placebo and anticoagulation }\end{array}$ & $\begin{array}{l}\text { Systemic thrombolysis } \\
\text { reversed hemodynamic } \\
\text { decompensation but increased } \\
\text { major hemorrhage and stroke }\end{array}$ \\
\hline $\begin{array}{l}\text { Kline et al. (7), Tenecteplase } \\
\text { or Placebo: Cardiopulmonary } \\
\text { Outcomes At Three Months } \\
\text { (TOPCOAT) }\end{array}$ & $\begin{array}{l}\text { Randomized } \\
\text { controlled }\end{array}$ & $\begin{array}{l}83 \text { patients with } \\
\text { submassive PE }\end{array}$ & $\begin{array}{l}\text { Arm 1: systemic thrombolysis } \\
\text { and anticoagulation; arm 2: } \\
\text { placebo and anticoagulation }\end{array}$ & $\begin{array}{l}\text { Systemic thrombolysis led to } \\
\text { better patient outcomes at } \\
3 \text { months but } 1 \text { fatal } \\
\text { intracranial hemorrhage }\end{array}$ \\
\hline $\begin{array}{l}\text { Sharifi et al. (8), MOderate } \\
\text { Pulmonary Embolism Treated with } \\
\text { Thrombolysis (MOPETT) }\end{array}$ & $\begin{array}{l}\text { Randomized } \\
\text { controlled }\end{array}$ & $\begin{array}{l}121 \text { patients with } \\
\text { submassive } P E\end{array}$ & $\begin{array}{l}\text { Arm 1: reduced dose tPA } \\
\text { plus anticoagulation; arm 2: } \\
\text { anticoagulation alone }\end{array}$ & $\begin{array}{l}\text { Trend for reduced death and } \\
\text { recurrent PE in systemic } \\
\text { tPA group; no bleeding } \\
\text { complications }\end{array}$ \\
\hline $\begin{array}{l}\text { Kucher et al. (9), Ultrasound- } \\
\text { Assisted Catheter Directed } \\
\text { Thrombolysis for Acute } \\
\text { Intermediate-Risk Pulmonary } \\
\text { Embolism (ULTIMA) }\end{array}$ & $\begin{array}{l}\text { Randomized } \\
\text { controlled }\end{array}$ & $\begin{array}{l}59 \text { patients with } \\
\text { submassive } P E\end{array}$ & $\begin{array}{l}\text { Arm 1: ultrasound- } \\
\text { assisted catheter-directed } \\
\text { thrombolysis; arm 2: } \\
\text { anticoagulation alone }\end{array}$ & $\begin{array}{l}\text { Ultrasound-assisted catheter- } \\
\text { directed thrombolysis } \\
\text { improved right ventricular } \\
\text { parameters without increased } \\
\text { risk of death, major bleeding, } \\
\text { or intracranial hemorrhage }\end{array}$ \\
\hline $\begin{array}{l}\text { Piazza et al. (10), Prospective, } \\
\text { Single-arm, Multi-Center Trial of } \\
\text { EkoSonic } ₫ \text { Endovascular System } \\
\text { and Activase for Treatment of Acute } \\
\text { Pulmonary Embolism (SEATTLE II) }\end{array}$ & $\begin{array}{l}\text { Prospective } \\
\text { single arm }\end{array}$ & $\begin{array}{l}150 \text { patients } \\
\text { with massive or } \\
\text { submassive PE }\end{array}$ & $\begin{array}{l}\text { Arm 1: } 24 \text { mg tPA via } \\
\text { ultrasound-assisted catheter } \\
\text { thrombolysis }\end{array}$ & $\begin{array}{l}\text { Ultrasound-assisted catheter- } \\
\text { directed thrombolysis reversed } \\
\text { hemodynamic compromise } \\
\text { and decreased pulmonary } \\
\text { arterial pressure, but } 11 \% \text { had } \\
\text { bleeding complications }\end{array}$ \\
\hline
\end{tabular}

PE, pulmonary embolism; IVC, inferior vena cava; DVT, deep vein thrombosis; tPA, tissue plasminogen activator.

mortality. Myocardial necrosis is considered when troponin $\mathrm{T}>0.1 \mathrm{ng} / \mathrm{mL}$. Troponin elevation as low as $>0.01 \mathrm{ng} / \mathrm{mL}$ predicts adverse events including right ventricular dysfunction (RVD), myocardial necrosis, and shortterm mortality (15). BNP $>90 \mathrm{pg} / \mathrm{mL}$ is an indicator of mortality (16). Electrocardiographic changes including new right bundle branch block, anteroseptal ST changes, and anteroseptal T-wave inversion can indicate RVD (17). $\mathrm{RV}$ dilation (apical four-chamber RV diameter divided by $\mathrm{LV}$ diameter $>0.9$ ) or RV systolic dysfunction on echocardiography are signs of RVD (17).

\section{Management}

The mortality of PE depends on clinical presentation, categorized into massive (high risk), submassive (intermediate risk), and low risk. Massive PE is defined by hemodynamic instability with signs of hypotension (systolic pressure $<90 \mathrm{mmHg}$ ) or shock, whereas submassive PE presents with signs of RVD or myocardial necrosis without hemodynamic instability (1).

Therapeutic options for massive and submassive $\mathrm{PE}$ include surgical thromboembolectomy, systemic 
thrombolysis, and CDI. Therefore, several subspecialties are involved in the treatment of $\mathrm{PE}$, necessitating a multidisciplinary team approach. In the setting of acute $\mathrm{PE}, \mathrm{RVD}$ is a poor prognostic indicator $(18,19)$. Therefore, prompt diagnosis and protocols set for treatment by a PE Response Team (PERT), are critical for the restoration of normal cardiac output and resolution of RVD (20).

Existing algorithms guide management based on severity. The American Heart Association (AHA) recommends systemic fibrinolysis for patients with massive $\mathrm{PE}$ and acceptable risk of bleeding, and considers it in patients presenting with submassive $\mathrm{PE}$ and low risk of bleeding (17). The European Society of Cardiology recommends therapies that restore perfusion, such as CDI, thrombolysis, or surgical thromboembolectomy, for treatment of massive $\mathrm{PE}$, and anticoagulation therapy for low risk and submassive PE (21). Surgical thromboembolectomy, recommended by AHA in the setting of massive PE and contraindication to fibrinolytics, is the most invasive therapy, carrying a mortality rate approaching $20 \%$ compared to $50 \%$ in the untreated population $(4,17)$.

Current algorithms do not incorporate CDI due to the paucity of prospective clinical trials. Because of the risks associated with both surgery and fibrinolysis, less invasive and targeted therapies have regained popularity $(17,22)$.

\section{Catheter-directed techniques}

Despite limited data, CDI has been practiced for several decades: the FDA approved the Greenfield suction catheter for PE treatment in 1969. Currently, numerous devices employing various mechanisms to eradicate thrombus in the pulmonary arteries (PAs) are used. These utilize fragmentation, aspiration, mechanical thrombectomy, thrombolysis or a combination of these methods. The treatment endpoint is reversal of hemodynamic instability for massive $\mathrm{PE}$, reversal of RVD and normalization of PA pressure in submassive PE, measured on echocardiography (9).

\section{Catheter-mediated thrombus fragmentation}

Several methods exist for PA thrombus fragmentation. The most widely used method is thromboembolus fragmentation by manual rotation of a pigtail catheter in the main, right, or left PA (23). Using the rotating pigtail catheter method, one group achieved an average of $33 \%$ recanalization through the thrombosed vessel, with concomitant reduction in PA pressure and shock index (24).

Newer devices are now available, such as the 8-Fr mechanical aspiration Aspirex1 Aspiration Thrombectomy Catheter (Straub Medical, Switzerland), which, similar to the AngioJet (Possis Medical, Inc., Minneapolis, Minnesota, USA), employs the Bernoulli hemodynamic principle (see below). To use this device, a long 8 -Fr introducer sheath is placed in the thrombus-laden PA. The Aspirex1 catheter can be placed over an 0.018-inch exchange-length wire into the proximal thrombus. The catheter is advanced over the wire in thrombectomy mode through the thrombus. This can be repeated several times with possible endpoints of improved hemodynamics or improvement in oxygenation. One study of 30 patients with massive and submassive PE reported a complete clearance rate of $>90 \%$ in over $80 \%$ of patients, with improvement in right heart strain; there were two major (bradycardia) and four minor (two access site hematomas, and two hemoptysis) procedure-related complications (25).

\section{Rheolytic thrombectomy}

Rheolytic thrombectomy involves thromboembolus fragmentation using a saline jet directed from the tip of the catheter with simultaneous emulsified thrombus removal via a separate channel. Available devices include the Amplatz thrombectomy device (Microvena, White Bear Lake, MN, USA), the cordis hydrolyser hydrodynamics thrombectomy catheter (Cordis, Johnson and Johnson, Japan), the Oasis Thrombectomy System (Boston Scientific Corporation, Natick, MA, USA), and the AngioJet Rapid Thrombectomy System. The AngioJet system employs Bernoulli hydrodynamics: high velocity moving fluid has low central pressure, creating a vacuum, with preferential movement of surrounding molecules into the center of the fluid. The AngioJet device rapidly infuses heparinized saline, up to $360 \mathrm{mph}$, via the catheter endhole, reducing local pressure to a $-600 \mathrm{mmHg}$, extracting soft thrombus into the catheter via a distal sideport (26).

The AngioJet device has pulse spray and thrombectomy modes. Initially, the catheter can be moved slowly back and forth in the affected main or lobar PA in pulse spray mode to infuse low dose tissue plasminogen activator (tPA) (18-20 mg mixed in $100 \mathrm{~mL}$ normal saline) throughout the thrombus (Figure 1). Following a prolonged pause, in regular mode, the catheter is again advanced and retracted within the thrombus in thrombectomy mode to aspirate clot (26). Immediate post-thrombectomy repeat pulmonary 

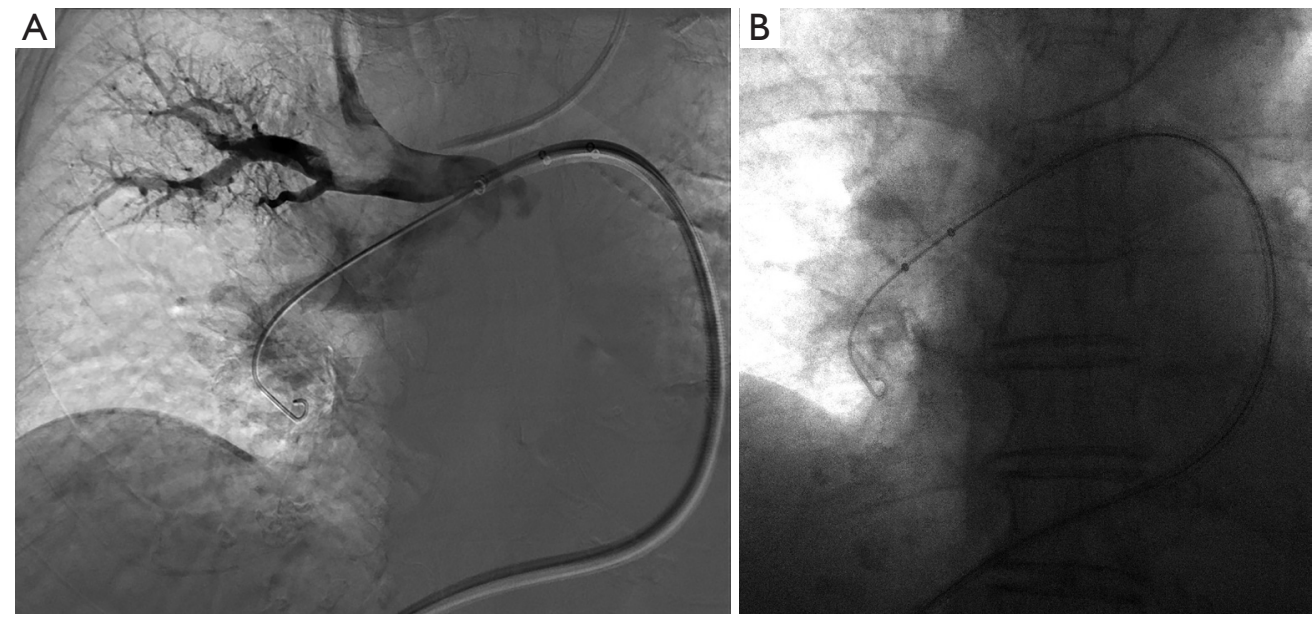

Figure 1 Rheolytic aspiration with AngioJet Thrombectomy System. (A) Single DSA image demonstrates a Rosen wire in a right lower lobar pulmonary artery, with a sheath in the right main pulmonary artery. Contrast injection demonstrates extensive clot burden in the right upper and lower lobar pulmonary arteries (PAs); (B) single fluoroscopic image demonstrates the AngioJet catheter in the right lower lobar pulmonary artery thrombus.

angiography and pressure measurements can confirm treatment effectiveness (26). Several deaths were reported early in the experience of AngioJet thrombectomy for PE, prompting a black-box warning label for its use in the PA circulation by the FDA. In one meta-analysis, AngioJet was associated with a high rate (28\%) of major complications, including bradyarrhythmias, heart block, hemoglobinuria, temporary renal insufficiency, hemoptysis, and major hemorrhage, with 5 of 68 patients with procedure-related deaths (23). Some nonetheless advocate for its use as a second line option for PE, given prior success $(27,28)$. The procedure should be done under an anesthesiologist's care, and with consideration of frequent breaks during the mechanical thrombolysis to allow recuperation of the heart rate, preventing profound bradycardia.

\section{Catheter-mediated thromboembolus aspiration}

The Greenfield embolectomy device (Medi-Tech/ Boston Scientific, Watertown, MA, USA) was the first catheter designed for percutaneous embolectomy via thromboaspiration. It is no longer commercially available due to its large profile necessitating venous cut down or direct surgical PA access, and challenging steerability, which limited its use. Newer large bore catheters, such as the AngioVac device (Vortex Medical, Inc., Norwell, MA, USA), are available but also hampered by bulky size requiring 24-Fr introducer sheath access, difficulty accessing the $\mathrm{PA}$, and requirement of veno-venous bypass (29). The AngioVac may have special application for treating IVC thrombosis in the setting of $\mathrm{PE}$ and can result in resolution of significant thrombus burden captured in an extracorporeal filter using veno-venous bypass and cardiac pump (Figure 2).

Modern suction thrombectomy catheters, including the Pronto XL extraction catheter (Vascular Solutions, Minneapolis, MN, USA), available in 10-, 12- and 14-Fr sizes, are reportedly effective in acute massive $\mathrm{PE}$ by reducing the visible thrombus or the mean PA pressure (30). Its pigtail shape can be used for thromboembolus extraction from the main PA, and the straight tip version from segmental PAs. The pigtail version can also be used like a rotational catheter to manually fragment thrombus, simultaneously suctioning clot via distal sideholes using a $60-\mathrm{mL}$ syringe. This device is FDA-approved for peripheral application; similar to newer devices, like the FlowTreiver (Inari Medical, Irvine, CA, USA) and Indigo (Penumbra Inc., Alameda, CA, USA), it is investigational in the PA.

\section{Catheter-directed thrombolysis via infusion catheters}

Though catheter-directed thrombolysis via multi-sidehole infusion catheters is the least technically challenging, its relative superiority is currently unknown. In one randomized controlled trial for massive $\mathrm{PE}$, there was no difference in angiography-documented post-treatment 

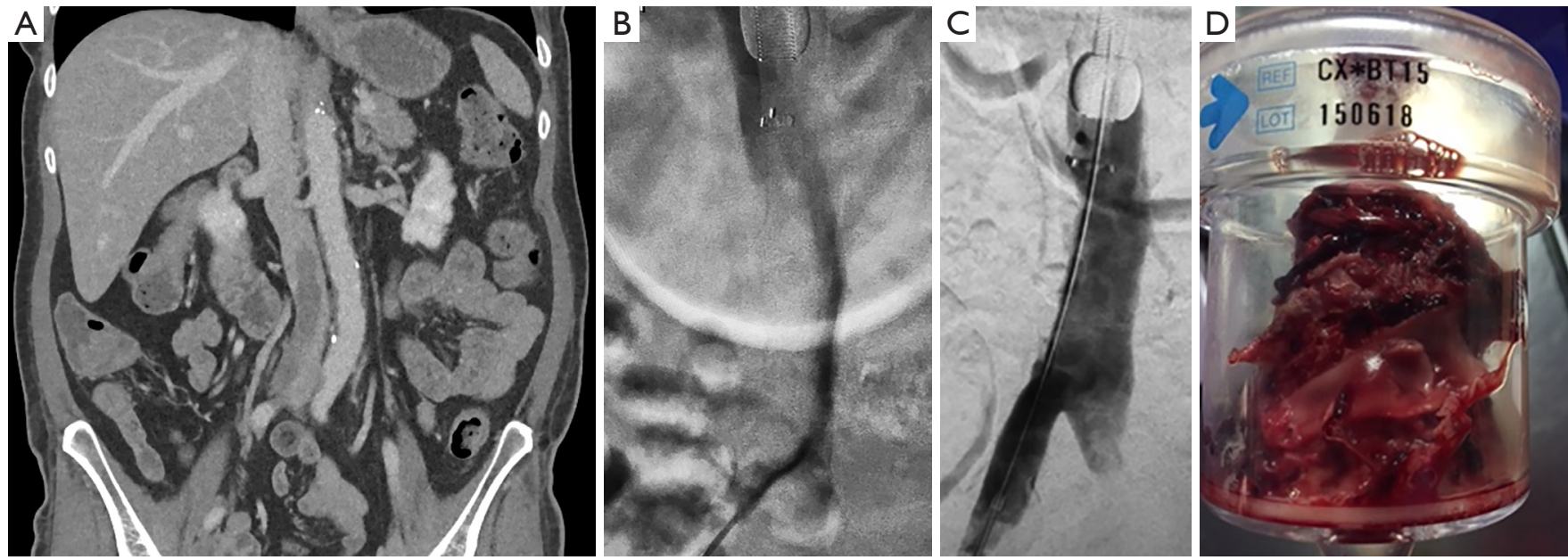

Figure 2 AngioVac clearance of IVC thrombus. (A) Coronal reformatted image of a contrast-enhanced abdominal CT demonstrates thrombus in the IVC; (B) contrast inferior cavogram demonstrates extensive thrombus burden. The AngioVac device is seen in the superior IVC; (C) post-thrombectomy venagram demonstrates resolution of the thrombus; (D) clot has been captured in the veno-venous bypass filter. IVC, inferior vena cava.

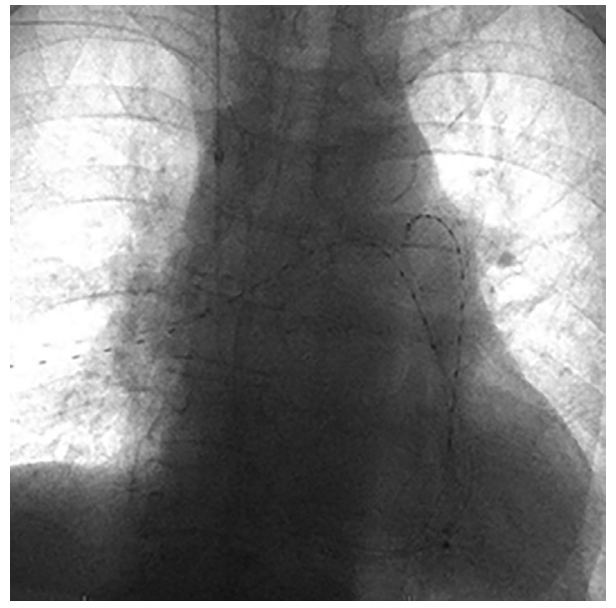

Figure 3 EKOS catheter-directed thrombolysis. Single fluoroscopic image demonstrates ultrasound-accelerated multisidehole infusion catheters placed within each pulmonary artery.

PE severity, comparing systemic and intrapulmonary administration of $50 \mathrm{mg}$ tPA over 2 hours (31). However, infusion of tPA over 7 hours, regardless of administration route, was superior to a 2-hour infusion (31).

Ultrasound-assisted thrombolytic infusion catheters achieve accelerated thrombolysis using ultrasound waves. The EndoWave System (EKOS corporation, Bothwell, MA, USA) consists of a 5 -Fr $106-\mathrm{cm}$ long catheter containing microinfusion pores within the $6-50 \mathrm{~cm}$ treatment segment of the catheter that optimize the interface of thrombus with an ultrasound core wire that contains small transducers allowing for delivery of ultrasound waves to the thromboembolus (Figure 3). Following access to the $\mathrm{PA}$ and angiographic examination, exchange is made over a 0.035-inch guidewire for EndoWave catheters containing the ultrasound core wire. The catheter also contains a port for tPA infusion (e.g., $0.5 \mathrm{mg}$ /hour per catheter if bilateral, or $1 \mathrm{mg}$ /hour per unilateral catheter), a port for saline to cool heat generated by the ultrasound waves, and an interface cable connected to a control unit in order to deliver ultrasound waves (9). Typically, tPA administration is performed over $18-24$ hours. The duration is shortened for fibrinogen levels $<150 \mathrm{mg} / \mathrm{dL}$ (32). Heparin infusion (200-300 units/hour per sheath) through the access sheath during the treatment retards new clot formation around the treatment devices (9).

One study showed an advantage of the EKOS system compared to catheter-directed thrombolysis alone in achieving thromboembolus removal in $100 \%$ of cases and reduction of removal time by approximately 8 hours (33). Moreover, the Ultrasound-Assisted Catheter Directed Thrombolysis for Acute Intermediate-Risk Pulmonary Embolism (ULTIMA) trial showed improvement in the right ventricular parameters without increased risk of death, major bleeding, or intracranial hemorrhage in submassive PE (9). 


\section{CDI technical pearls}

\section{Contraindications to $P A$ catbeterization}

Interventional radiologists should be aware of contraindications to PA catheterization when discussing the possibility of CDI, including: tricuspid or pulmonary valve prosthesis or vegetation, recent myocardial infarction, and left bundle branch block as catheterization could cause a complete block requiring temporary pacemaker placement. Relative contraindications include contrast allergy and history of ventricular irritability, which may be discussed with the anesthesiologist.

\section{Contraindications to thrombolysis}

An understanding of the pharmacology of heparin and tPA informs appropriate patient selection for CDI for PE. Whereas tPA promotes plasmin-mediated fibrinolysis, dissolving clot, heparin is an anticoagulant acting on the intrinsic pathway, inhibiting coagulation and preventing thrombus progression without leading to its dissolution. The biological half-life of tPA and intravenous heparin is approximately 8 and 60 minutes, respectively (34,35). Whereas tPA is the active medication used to treat $\mathrm{PE}$, heparin is also delivered at a low dose to prevent clot formation in and around access sheaths and catheters.

Though tPA is administered locally in the PA during CDI for PE, it produces some systemic impact on fibrinolytic cascades, putting patients at risk for hemorrhage elsewhere in the body. Use of thrombolytics is therefore contraindicated in the setting of prior ischemic stroke, intracranial hemorrhage, intracranial mass or vascular malformation, recent neurological, major abdominal or pelvic surgery, gastrointestinal ulcer, or any source of active bleeding or bleeding diathesis. Some centers obtain a noncontrast CT of the brain prior to tPA administration to assess for potential intracranial hemorrhage. For patients with contraindications to tPA, mechanical techniques such as rotating pigtail-catheter clot maceration may be considered alternatively.

\section{Access site}

Any venous access may be used, though the right common femoral (most common), the right upper arm, or the right internal or external jugular vein are typical at our institution. Using the arm or neck approach rather than the groin may increase patient comfort and decrease risk of access site hematoma. In one study, the use of femoral vein access was the only variable associated with major bleeding, compared to a brachial access (36). A short 7-10 Fr introducer sheath is usually adequate $(9,10,27)$. Though, using a long sheath placed in the main PA can facilitate exchanges for catheter and thromboembolectomy devices.

\section{Techniques for PA catheterization}

To catheterize the PA, a pigtail type catheter is most commonly used at our institution to decrease arrhythmogenic wire manipulation in the right heart (37). This is almost always inserted via an appropriately sized introducer sheath. Through the jugular or upper arm venous access, preshaped catheters including the Hunter catheter (Cook Inc., Bloomington, IN, USA) or Swan-Ganz-type catheters can be used to access each PA (38). Given the need for bilateral PA access and treatment, femoral vein access affords the use of a single access using a dual-lumen introducer sheath (Fast-Cath Duo Hemostasis Introducer Sheath, St. Jude Medical, St. Paul, MN, USA), which accommodates two catheters in a singular chamber.

Alternatively, a pigtail catheter can be used via the brachiocephalic or femoral venous access, preferably a 7-Fr size due to its relative rigidity and maneuverability. One technique to ease PA catheterization via the femoral access is to use the stiff back-portion of a guidewire, such as a Bentson wire (Cook Inc., Bloomington, IN, USA), which may be bent to create a smooth P-shape curve on the pigtail. This or a tip-deflecting wire can be placed within centimeters of the looped portion of a pigtail catheter to create an approximately $90^{\circ}$ angled curve. When advanced immediately superior to the inferior cavoatrial junction, the pigtail portion of the catheter usually proceeds from the right atrium through the tricuspid valve into the $R V$. When in the $R V$, the wire is retracted, allowing for straightening of the catheter where, once rotated and advanced, can be landed in the main PA. After reaching the $\mathrm{RV}$, the catheter is rotated counterclockwise to introduce the pigtail catheter into the main PA. Alternatively, preshaped catheters such as a Grollman, Monti, or Van Aman catheters (Cook Inc., Bloomington, IN, USA), may be used (Figure 4). These contain fixed curves that can be manipulated across the tricuspid valve into the main PA (39). Another technique involves an Omniflush catheter (AngioDynamics, Queensbury, NY, USA) and a J-tip wire such as a Rosen wire (Cook Inc., Bloomington, IN, USA), used to catheterize the RV. By advancing more wire into the tip of 


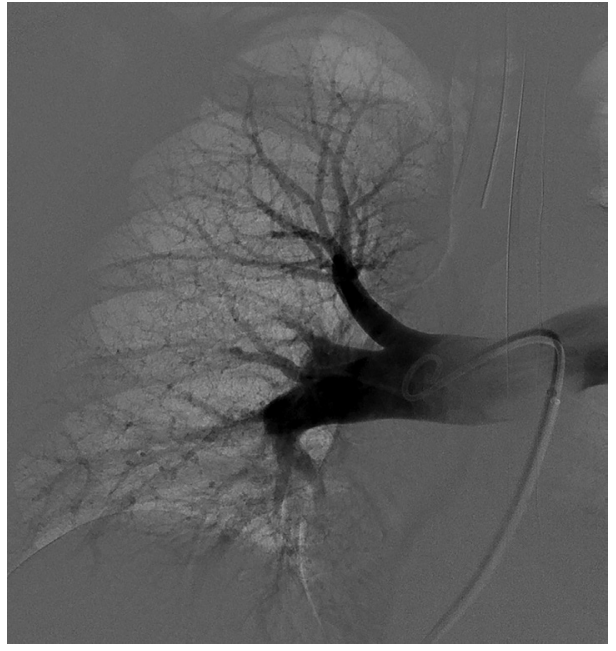

Figure 4 Pulmonary artery catheterization with Grollman catheter. Right pulmonary arteriogram is performed with a Grollman catheter, with a 90 degree curve several centimeters before the pigtail to facilitate pulmonary arterial catheterization.

the OminiFlush catheter, the tip is opened to 90 degrees and turned toward the RV at which point the wire is advanced followed by the catheter. However, this technique is prone to more arrhythmias (40).

Gentle wire manipulation can be performed to catheterize the pulmonary outflow tract. Once the main $\mathrm{PA}$ is catheterized, due to the angles of the left and right PA, the catheter will more often land in the left PA. However, using a guidewire and the diagnostic catheter, catheterization from the left to the right PA can be accessed over the wire. If using a pigtail catheter, the P-shape of the back end of a Bentson wire can be re-used, along with catheter retraction into the main PA, then rotated clockwise and advanced into the right PA. The front end of the wire can also be used, with adequate pigtail catheter retraction into the main PA, with proper alignment of its end hole towards the right PA. Care should be taken not to inadvertently over-retract the catheter as it may land within the RV, necessitating repeat catheter manipulation into the main PA, with the potentially associated increased risk of cardiac arrhythmias. Other pre-shaped catheters can also be manipulated from the left to the right PA using initial catheter retraction (into the main PA), followed by catheter rotation and advancement. Finally, exchange can be made over an adequately long $(260 \mathrm{~cm})$ stable wire for a multi-sidehole infusion catheters, placed within each PA for treatment.

\section{Measuring $P A$ pressure}

In the setting of acute PE, RV and PA measurements can serve as a baseline to guide therapy. PA pressure can be measured anywhere within the main, left, or right PA, using a multi-side hole catheter. In the acute setting, to avoid overwhelming the heart, balloon-tipped catheters, often used for pressure assessment in the setting of PE, are avoided (41). Rather, multi-sidehole catheters are preferred. Using the latter also allows for power contrast injection (41). Normal RA pressures are $0-5 \mathrm{mmHg}$; $\mathrm{RV}$ pressures are $20-25 \mathrm{mmHg}$; and $\mathrm{PA}$ pressures are 20-25 mmHg systolic and $10-15 \mathrm{mmHg}$ diastolic, with a mean pressure of 9-18 $\mathrm{mmHg}$. In the case of elevated PA pressures, high volume injections for pulmonary angiography are best avoided (42). Suggested injection rates from the experience at our institution include $20 \mathrm{~mL} / \mathrm{sec}$ over $1 \mathrm{sec}$ in the lobar arteries, which could be lowered to $10 \mathrm{~mL} / \mathrm{sec}$ for $2 \mathrm{sec}$ in the lobar PAs if pulmonary hypertension is present $(17,43)$. The imaging frame rate should be at least 3 frames/sec, to delineate adequate detail. Care should be taken to decrease the volume and rate of contrast injection with increasing degrees of elevation of the mean PA pressure. The authors advocate unilateral PA contrast power injections, with a maximal rate of $20 \mathrm{~mL} / \mathrm{sec}$ $\times 1 \mathrm{sec}$, with rate and volume decrease for each incremental increase in the mean PA pressure. An additional benefit of lobar contrast examination is the better resolution of imaging of a single arterial distribution compared to the entire, left and right PA tree (Figure 5). For right pulmonary angiography, the distal pigtail or the infusion side- and endholes of the catheter used should be left proximal to the pulmonary arterial branch to the right upper lobe as it often emanates early from the main PA.

\section{Intraprocedural placement of an IVC filter}

Current guidelines do not recommend routine intraprocedural placement of IVC filters in the setting of PE $(17,21)$. One retrospective study suggested that IVC filter placement reduced 90-day mortality in patients with massive PE (44). Another retrospective study showed that IVC filter placement reduced in-hospital mortality for patients with $\mathrm{PE}$ who received anticoagulation or thrombolysis (45). However, the more recent prospective Prevention of Recurrent Pulmonary Embolism by Vena Cava Interruption 2 (PREPIC2) study, which randomized patients with symptomatic $\mathrm{PE}$ and lower extremity deep vein thrombosis 

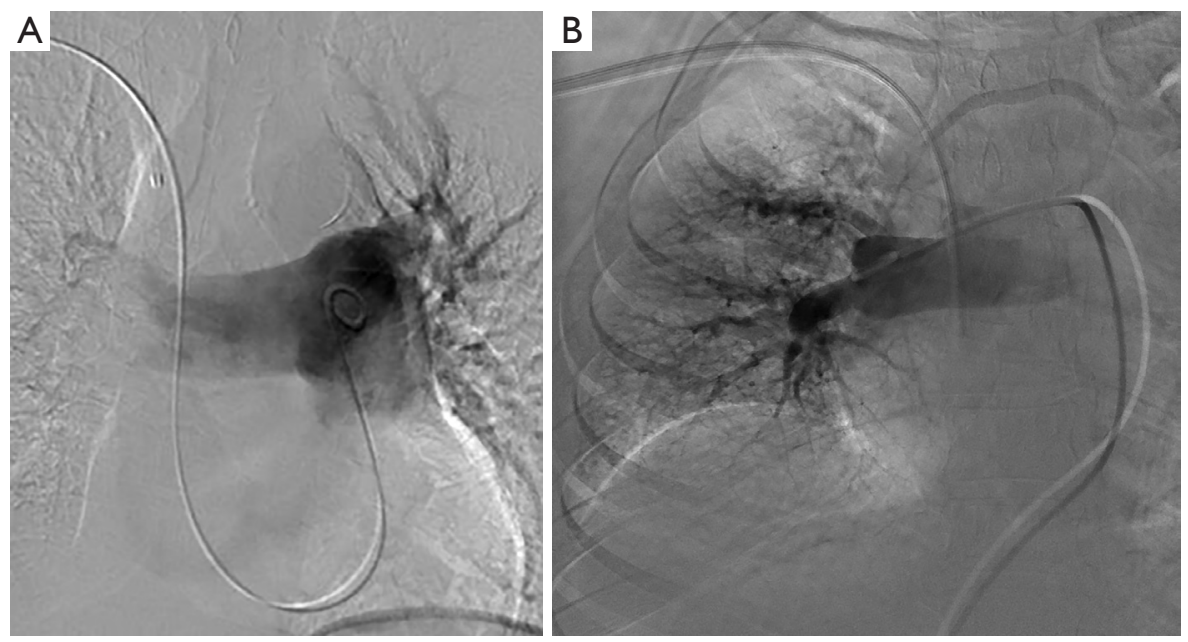

Figure 5 Pulmonary arteriography. (A) Imaging can be obtained by placing the pigtail catheter in the main pulmonary artery; (B) selective angiography is superior; lobar injection typically provides greater detail of thrombus burden, compared with main pulmonary arterial injections.

(DVT) to either anticoagulation alone or anticoagulation with IVC filter placement showed no difference in the rate of recurrent PE between groups (5). Therefore, the use of IVC filters adjunctively with CDI cannot be recommended nor refuted on the basis of current evidence.

\section{Patient monitoring and follow-up}

Monitoring during the tPA infusion period is essential and necessitates admission to an intensive care unit or similar level of care. More conservative protocols include an initial complete blood count, INR, and fibrinogen repeated every 4 hours (46) and a pre-procedural type and screen. Due to the fear of bleeding caused by overconsumption of clotting factor during tPA infusion and therefore increased risk of hemorrhage, fibrinogen values are strictly followed (32). Most conservative protocols call for a temporary halt (or halving of the infusion rate) of thrombolytics once fibrinogen $<200 \mathrm{mg} / \mathrm{dL}$, and advocate stopping it completely when fibrinogen $<150 \mathrm{mg} / \mathrm{dL}$ (32). Frequent physical examination, including neurological checks, may alert clinicians of occult adverse hemorrhagic complications, especially in the cerebral circulation.

Endpoints for thrombolysis include a maximum tPA dose (e.g., 18-24 mg), an 18-24-hour infusion period, or improved hemodynamics by echocardiography, computed tomography angiography (CTA) or conventional pulmonary angiogram. Once the clinical goal is achieved, the catheters may be removed without repeat imaging (9). After CDI, access sheaths are usually removed following discontinuation of the thrombolysis and heparin. To decrease the risk of access site hematoma, sheath removal may be delayed by a few hours (47). Measurement of activated clotting time can assess proper timing of sheath removal if necessary, or removal can be attempted after at least two half-lives of heparin.

\section{Clinical evidence}

Despite a trend towards decreased mortality, systemic fibrinolysis carries a higher risk of bleeding compared to anticoagulation alone. In the randomized double blind Pulmonary Embolism THrOmbolysis (PEITHO) trial, 506 patients received fibrinolysis with tenecteplase and anticoagulation, and 499 patients received anticoagulation alone. Patients who received fibrinolysis and anticoagulation, compared to those that received only anticoagulation, had significantly decreased death or hemodynamic compromise $(2.6 \%$ vs. $5.6 \%)$, but significantly more extracranial bleeding $(6.3 \%$ vs. $1.2 \%)$ and hemorrhagic stroke ( $2.0 \%$ vs. $0.2 \%)(6)$. These results reinforced the findings of the similar, smaller randomized Tenecteplase or Placebo: Cardiopulmonary Outcomes At Three Months (TOPCOAT) trial, with 40 patients receiving tenecteplase and anticoagulation and 43 patients receiving anticoagulation alone; though the fibrinolysis 
group attained better composite outcomes, 1 patient (2.5\%) had a fatal intracranial hemorrhage (7). The prospective randomized MOderate Pulmonary Embolism Treated with Thrombolysis (MOPETT) trial investigated whether treating patients with a lower dose of systemic thrombolysis would still be effective and safer; no bleeding was observed in either group, though trends for decreased mortality and recurrent $\mathrm{PE}$ did not reach significance (8).

Three major trials established CDI as a valuable alternative to other treatments. The ULTIMA trial showed marked improvement in $\mathrm{RV}$ parameters without major complications in submassive PE (9). The Prospective, Single-arm, Multi-Center Trial of EkoSonic ${ }^{\circledR}$ Endovascular System and Activase for Treatment of Acute Pulmonary Embolism (SEATTLE II) trial, a single arm prospective study of 150 patients, showed a reduction in RVD and improvement in pulmonary hypertension in submassive and massive PE without any intracranial hemorrhage (10). The multicenter Pulmonary Embolism Response to Fragmentation, Embolectomy, and Catheter Thrombolysis (PERFECT) registry evaluated CDI for massive and submassive PE (11). Clinical success was regarded as stabilization of hemodynamics, improvement in pulmonary hypertension, and survival to discharge date. Clinical success rate was $86 \%$ for massive and $97 \%$ for submassive $\mathrm{PE}$, with improvement in pulmonary hypertension and RV strain without major hemorrhagic complications (11). As a result of adaptation of a PERT, one study reported an increased number of patients appropriately treated with CDI with resultant reduced mortality compared to the national registry (48). Indeed, PERT has become a standard of in-hospital care (20).

Further prospective data is needed to delineate: (I) which patients may benefit from CDI compared with systemic thrombolysis; (II) what clinical and laboratory features distinguish these patients; and, (III) which of the CDI techniques is superior in regard to treatment efficacy and safety. Multicenter and multidisciplinary cooperation is required.

\section{Conclusions}

$\mathrm{PE}$ is a life-threatening but potentially treatable clinical entity. Anticoagulation therapy is the first line recommended treatment for acute PE (17). In massive and submassive PE, reversal of RVD, restoration of normal hemodynamics, and increased survival are the goals of management. Because anticoagulation alone often fails to improve
RVD in a timely fashion, and systemic thrombolysis and surgical thrombectomy carry high rates of morbidity and mortality, there has been a reemergence of interest in catheter-directed techniques. Newer guidelines employ CDI in treatment protocols. In addition, the FDA recently approved ultrasound-accelerated catheter-directed thrombolysis for the treatment of PE. CDI has become a vital tool in the treatment of massive and submassive $\mathrm{PE}$ at many institutions.

\section{Acknowledgements}

None.

\section{Footnote}

Conflicts of Interest: The authors have no conflicts of interest to declare.

\section{References}

1. Office of the Surgeon General (US); National Heart, Lung, and Blood Institute (US). The Surgeon General's Call to Action to Prevent Deep Vein Thrombosis and Pulmonary Embolism. Rockville (MD): Office of the Surgeon General (US), 2008. Available online: https:// www.ncbi.nlm.nih.gov/books/NBK44178/

2. Goldhaber SZ, Visani L, De Rosa M. Acute pulmonary embolism: clinical outcomes in the International Cooperative Pulmonary Embolism Registry (ICOPER). Lancet 1999;353:1386-9.

3. Sista AK, Kearon C. Catheter-Directed Thrombolysis for Pulmonary Embolism: Where Do We Stand? JACC Cardiovasc Interv 2015;8:1393-5.

4. Neely RC, Byrne JG, Gosev I, et al. Surgical Embolectomy for Acute Massive and Submassive Pulmonary Embolism in a Series of 115 Patients. Ann Thorac Surg 2015;100:124551; discussion 1251-2.

5. Mismetti P, Laporte S, Pellerin O, et al. Effect of a retrievable inferior vena cava filter plus anticoagulation vs anticoagulation alone on risk of recurrent pulmonary embolism: a randomized clinical trial. JAMA 2015;313:1627-35.

6. Meyer G, Vicaut E, Danays T, et al. Fibrinolysis for patients with intermediate-risk pulmonary embolism. $\mathrm{N}$ Engl J Med 2014;370:1402-11.

7. Kline J, Hernandez J, Kabrhel C, et al. Randomized trial of tenecteplase or placebo with low molecular weight heparin 
for acute submassive pulmonary embolism: assessment of patient-oriented cardiopulmonary outcomes at three months. J Am Coll Cardiol 2013;61. doi:10.1016/S07351097(13)62074-4

8. Sharifi M, Bay C, Skrocki L, et al. Moderate pulmonary embolism treated with thrombolysis (from the "MOPETT" Trial). Am J Cardiol 2013;111:273-7.

9. Kucher N, Boekstegers P, Müller OJ, et al. Randomized, controlled trial of ultrasound-assisted catheter-directed thrombolysis for acute intermediate-risk pulmonary embolism. Circulation 2014;129:479-86.

10. Piazza G, Hohlfelder B, Jaff MR, et al. A Prospective, Single-Arm, Multicenter Trial of Ultrasound-Facilitated, Catheter-Directed, Low-Dose Fibrinolysis for Acute Massive and Submassive Pulmonary Embolism: The SEATTLE II Study. JACC Cardiovasc Interv 2015;8:1382-92.

11. Kuo WT, Banerjee A, Kim PS, et al. Pulmonary Embolism Response to Fragmentation, Embolectomy, and Catheter Thrombolysis (PERFECT): Initial Results From a Prospective Multicenter Registry. Chest 2015;148:667-73.

12. Weiss CR, Scatarige JC, Diette GB, et al. CT pulmonary angiography is the first-line imaging test for acute pulmonary embolism: a survey of US clinicians. Acad Radiol 2006;13:434-46.

13. Araoz PA, Gotway MB, Harrington JR, et al. Pulmonary embolism: prognostic CT findings. Radiology 2007;242:889-97.

14. Wang F, Fang W, Lv B, et al. Comparison of lung scintigraphy with multi-slice spiral computed tomography in the diagnosis of pulmonary embolism. Clin Nucl Med 2009;34:424-7.

15. Becattini C, Vedovati MC, Agnelli G. Prognostic value of troponins in acute pulmonary embolism: a meta-analysis. Circulation 2007;116:427-33.

16. Kucher N, Printzen G, Goldhaber SZ. Prognostic role of brain natriuretic peptide in acute pulmonary embolism. Circulation 2003;107:2545-7.

17. Jaff MR, McMurtry MS, Archer SL, et al. Management of massive and submassive pulmonary embolism, iliofemoral deep vein thrombosis, and chronic thromboembolic pulmonary hypertension: a scientific statement from the American Heart Association. Circulation 2011;123:1788-830.

18. Samaranayake CB, Royle G, Jackson S, et al. Right ventricular dysfunction and pulmonary hypertension following sub-massive pulmonary embolism. Clin Respir J
2015. [Epub ahead of print].

19. Zhu L, Yang Y, Wu Y, et al. Value of right ventricular dysfunction for prognosis in pulmonary embolism. Int $\mathrm{J}$ Cardiol 2008;127:40-5.

20. Reza N, Dudzinski DM. Pulmonary embolism response teams. Curr Treat Options Cardiovasc Med 2015;17:387.

21. Konstantinides SV, Torbicki A, Agnelli G, et al. 2014 ESC guidelines on the diagnosis and management of acute pulmonary embolism. Eur Heart J 2014;35:3033-69, 3069a-3069k.

22. Kucher N. Catheter embolectomy for acute pulmonary embolism. Chest 2007;132:657-63.

23. Kuo WT, Gould MK, Louie JD, et al. Catheter-directed therapy for the treatment of massive pulmonary embolism: systematic review and meta-analysis of modern techniques. J Vasc Interv Radiol 2009;20:1431-40.

24. Schmitz-Rode T, Janssens U, Duda SH, et al. Massive pulmonary embolism: percutaneous emergency treatment by pigtail rotation catheter. J Am Coll Cardiol 2000;36:375-80.

25. Dumantepe M, Teymen B, Akturk U, et al. Efficacy of rotational thrombectomy on the mortality of patients with massive and submassive pulmonary embolism. J Card Surg 2015;30:324-32.

26. Jaber WA, Fong PP, Weisz G, et al. Acute Pulmonary Embolism: With an Emphasis on an Interventional Approach. J Am Coll Cardiol 2016;67:991-1002.

27. Kokov LS, Matveev PD, Nikitina OV, et al. Use of thrombolytic therapy and rheolytic thrombectomy in treatment of pulmonary artery thromboembolism. Angiol Sosud Khir 2015;21:105-15.

28. Pelliccia F, Schiariti M, Terzano C, et al. Treatment of acute pulmonary embolism: update on newer pharmacologic and interventional strategies. Biomed Res Int 2014;2014:410341.

29. Sobieszczyk P. Catheter-assisted pulmonary embolectomy. Circulation 2012;126:1917-22.

30. Heberlein WE, Meek ME, Saleh O, et al. New generation aspiration catheter: Feasibility in the treatment of pulmonary embolism. World J Radiol 2013;5:430-5.

31. Verstraete M, Miller GA, Bounameaux H, et al. Intravenous and intrapulmonary recombinant tissue-type plasminogen activator in the treatment of acute massive pulmonary embolism. Circulation 1988;77:353-60.

32. Skeik N, Gits CC, Ehrenwald E, et al. Fibrinogen level as a surrogate for the outcome of thrombolytic therapy using tissue plasminogen activator for acute lower extremity intravascular thrombosis. Vasc Endovascular Surg 
2013;47:519-23.

33. Lin PH, Annambhotla S, Bechara CF, et al. Comparison of percutaneous ultrasound-accelerated thrombolysis versus catheter-directed thrombolysis in patients with acute massive pulmonary embolism. Vascular 2009;17 Suppl 3:S137-47.

34. Hirsh J, Warkentin TE, Raschke R, et al. Heparin and low-molecular-weight heparin: mechanisms of action, pharmacokinetics, dosing considerations, monitoring, efficacy, and safety. Chest 1998;114:489S-510S.

35. Holden RW. Plasminogen activators: pharmacology and therapy. Radiology 1990;174:993-1001.

36. Meyer G, Gisselbrecht M, Diehl JL, et al. Incidence and predictors of major hemorrhagic complications from thrombolytic therapy in patients with massive pulmonary embolism. Am J Med 1998;105:472-7.

37. Stein PD, Athanasoulis C, Alavi A, et al. Complications and validity of pulmonary angiography in acute pulmonary embolism. Circulation 1992;85:462-8.

38. Rosen G, Kowalik KJ, Ganguli S, et al. The Hunter pulmonary angiography catheter for a brachiocephalic vein approach. Cardiovasc Intervent Radiol 2006;29:997-1002.

39. Beachley MC, Tisnado J, Konerding K, et al. Alternate technique for pulmonary arteriography. AJR Am J Roentgenol 1980;134:195-6.

40. Velling TE, Brennan FJ, Hall LD. Pulmonary angiography with use of the 5-F omniflush catheter: a safe and efficient

Cite this article as: Zarghouni M, Charles HW, Maldonado TS, Deipolyi AR. Catheter-directed interventions for pulmonary embolism. Cardiovasc Diagn Ther 2016;6(6):651661. doi: 10.21037/cdt.2016.11.15 procedure with a common catheter. J Vasc Interv Radiol 2000;11:1005-8.

41. Grollman JH. Complications of pulmonary arteriography. Semin Intervent Radiol 1994;11:113-20.

42. Mills SR, Jackson DC, Older RA, et al. The incidence, etiologies, and avoidance of complications of pulmonary angiography in a large series. Radiology 1980;136:295-9.

43. Engelberger RP, Kucher N. Catheter-based reperfusion treatment of pulmonary embolism. Circulation 2011;124:2139-44.

44. Kucher N, Rossi E, De Rosa M, et al. Massive pulmonary embolism. Circulation 2006;113:577-82.

45. Isogai T, Yasunaga H, Matsui H, et al. Effectiveness of inferior vena cava filters on mortality as an adjuvant to antithrombotic therapy. Am J Med 2015;128:312.e23-31.

46. Gaba RC, Gundavaram MS, Parvinian A, et al. Efficacy and safety of flow-directed pulmonary artery catheter thrombolysis for treatment of submassive pulmonary embolism. AJR Am J Roentgenol 2014;202:1355-60.

47. Niederstadt JA. Frequency and timing of activated clotting time levels for sheath removal. J Nurs Care Qual 2004;19:34-8.

48. Kabrhel C, Rosovsky R, Channick R, et al. A Multidisciplinary Pulmonary Embolism Response Team: Initial 30-Month Experience With a Novel Approach to Delivery of Care to Patients With Submassive and Massive Pulmonary Embolism. Chest 2016;150:384-93. 